\title{
POLY (VINYL ALCOHOL)/ CARBOXYMETHYL CELLULOSE- SODIUM SALT/ CARROT FIBER-CONTAINING COMPOSITE THIN FILMS: THERMOMECHANICAL AND BIODEGRADATION STUDY
}

\author{
Seema Rani ${ }^{1,2}$, Kapil Gulati ${ }^{1,3}$, Neera $\operatorname{Raghav}^{1}$ and Sanjiv Arora ${ }^{1, \bowtie}$ \\ ${ }^{1}$ Department of Chemistry, Kurukshetra University, Kurukshetra-136119, Haryana, India \\ ${ }^{2}$ Department of Chemistry, Dr. B.R.A.Govt. College, Kaithal-136027, Haryana, India \\ ${ }^{3}$ Department of Chemistry, Dyal Singh College, Karnal-132001, Haryana, India \\ ${ }^{\otimes}$ Corresponding Author: sarora@kuk.ac.in
}

\begin{abstract}
Carrot (Daucus Carota L.) fiber consists of cellulosic substances and can be used to make biodegradable and economical packaging films. Biofilms of Polyvinyl alcohol (PVA) and Carboxymethyl cellulose-Na salt (CMC) with Carrot fiber (CF) have been synthesized by solution casting technique. Polyethylene glycol (PEG) is used as a plasticizer for a sustainable reaction medium. FTIR, UV-Visible, thermal analysis, SEM and tensile testing techniques have been used to analyze the films. The thermal decomposition of biofilms was studied by a thermogravimetric analyzer in a nitrogen atmosphere at a heating rate of $10{ }^{\circ} \mathrm{C} \mathrm{min}{ }^{-1}$ from ambient temperature to $600{ }^{\circ} \mathrm{C}$. Kinetic parameters were calculated using kinetic methods viz. Broido, Coats-Redfern and HorowitzMetzger. FTIR spectra give out the results for significant peak changes and are backed by UV-spectra to compare the optical properties of composites with neat PVA. Young's Modulus (MPa) and Tensile strength (MPa) values decrease with fiber addition to PVA/CMC. An optimal value of $12.5 \mathrm{wt} \%$ loading was obtained concerning tensile as well as thermal analysis data. Biodegradation studies were also performed in soil and compost. Route of degradation has been proposed based on spectral studies. It is concluded that the incorporation of carrot fibers in composites enhanced the degradation of PVA just like CMC and resulted in films with enhanced UV protection properties.
\end{abstract}

Keywords: Biocomposites, Carboxymethyl Cellulose, Degradation, Poly (Vinyl Alcohol), Thermal

RASĀYAN J. Chem., Vol. 14, No.4, 2021

\section{INTRODUCTION}

Because of growing environmental issues, non-biodegradable packaging materials necessitate being replaced by biodegradable polymer composites. ${ }^{1}$ The use of biodegradable films is gaining importance due to their low cost, lightness and lesser evil in terms of environmental pollution. ${ }^{2}$ Natural fibers reinforced polymer composites have their applications in packaging, automobiles and biomedical areas. ${ }^{3,4}$ Plant fibers are significant as a reinforcement material in polymer composites owing to their low cost, easy availability, friendly processing, no skin irritation and good thermal properties. ${ }^{5,6}$ By incorporating natural fibers or fillers to the polymeric materials increase their eco friendliness. ${ }^{7}$

Carrot (Daucus Carota L.) is affluent in dietary fibers and is an imperative root vegetable. ${ }^{8}$ After juicing tons of carrot residue are discarded as waste. Carrot residue in dry form consists of cellulosic substances and can be used to make biodegradable and economical packaging films. It has been reported that the dry carrot residue consists of $81 \%$ cellulose, $9 \%$ hemicelluloses, $2.5 \%$ lignin and $7.5 \%$ pectin $^{6,9}$ along with small amounts of lipids, proteins, carbohydrates, carotenes and minerals like $\mathrm{Fe}, \mathrm{Mg}, \mathrm{Ca}$ and $\mathrm{P} .{ }^{8}$

Polyvinyl alcohol (PVA) is a water-processable and biodegradable synthetic polymer with technological applications. Because of greater polarity, PVA is water-soluble and can be easily processed. The magnificent physical and optical properties of PVA composites have eventuated in their immense industrial uses. ${ }^{10}$ PVA is universally used because of its flexibility, film-forming competence, nontoxicity and high tensile strength. ${ }^{11,12}$ One of the cellulosic derivatives is $\mathrm{CMC}$ (in which $-\mathrm{CH}_{2} \mathrm{COOH}$ group is bound to some $-\mathrm{OH}$ group of natural cellulose) and adding CMC to PVA results in the improvement of its applications in the field of agriculture, food packaging as well as in drug delivery. By

Rasayan J. Chem., 14(4), 2224-2235(2021)

http://doi.org/10.31788/RJC.2021.1446445

This work is licensed under a CC BY 4.0 license. 
the addition of cellulosic fiber to PVA causes a change in physiochemical as well as the morphological properties of the PVA composites. ${ }^{10}$

In the present study, biocomposites of PVA/CMC blends with carrot fiber $(\mathrm{CF})$ as reinforcement are prepared. Carboxymethyl cellulose-Na salt (CMC) is used because of its biodegradability, viscosity and water-binding properties. ${ }^{13,14}$ To improve the flexibility of films, an aqueous solution of biocompatible plasticizer polyethylene glycol (PEG) is added as a green reaction medium. ${ }^{15}$ The boric acid solution was introduced to improve the antifungal resistance of composite films. ${ }^{16}$ In the present work, we have synthesized biocomposites of polyvinyl alcohol with carrot fiber as reinforcement material and carboxymethyl cellulose-Na salt (CMC) as a thickening agent. Thermal profiles of the composite thin films and evaluation of kinetic and thermal parameters by kinetic methods viz. Broido ${ }^{17}$, Coats-Redfern methods ${ }^{18}$ and Horowitz-Metzger ${ }^{19}$ are made. The optical, mechanical and degradable properties of these biocomposites are also studied.

\section{EXPERIMENTAL}

\section{Materials}

Carrot (Daucus Carota L.) is rich in dietary fibers and contains very high moisture content. Carrots were procured from the local market were washed properly. After juice extraction, carrot pulp was washed several times with distilled water and washed pulp was dried for 3 days at $60{ }^{\circ} \mathrm{C}$ in the oven. Dried carrot pulp was ground and after sieving 75 mesh size of the fiber was selected as filler in the polymer matrix. PVA (MW: 85,000-1,24,000) was purchased from Sd Fine-chem limited, carboxymethyl cellulose sodium salt was obtained from Loba-Chemie. Poly (ethylene glycol) average MW 6000 and boric acid were purchased from Hi-media.

\section{Methods}

Solution casting technique was used to prepare PVA/CMC/Carrot Fiber composite thin films using fiber loading of $0,5,7.5,10$ and $12.5 \mathrm{wt} \%$. Deionized water at $80{ }^{\circ} \mathrm{C}$ was used to dissolve PVA and CMC-Na salt was also dissolved in hot deionized water separately. CMC-Na salt solution was mixed in PVA solution with the help of a magnetic stirrer for $1 \mathrm{~h}$ and fiber of appropriate weight was mixed into the reaction mixture with continuous stirring for an hour. An aqueous solution of PEG was introduced to the reaction mixture and plasticization reaction continued for 20 minutes and boric acid $(0.8 \mathrm{wt} \%)$ was also added. The resulting mixture was sonicated in Ultracleaner Sonicator for an hour providing uniform distribution to the natural fibers. After cooling the solution to room temperature, the films were cast into clean Polypropylene dishes. Films were vacuum dried at $60{ }^{\circ} \mathrm{C}$ for $24 \mathrm{~h}$ and named as PVA, PVA/CMC, $\mathrm{PVA} / \mathrm{CMC} / \mathrm{CF}-5 \%$, PVA/CMC/CF-7.5\%, PVA/CMC/CF-10\% and PVA/CMC/CF-12.5\% corresponding to fiber loading.

\section{Characterization of Composite Thin Films}

The composite thin films of PVA/CMC/CF were characterized by FTIR, UV-Visible, thermogravimetric analyzer, SEM, biodegradation and tensile tests.

\section{Thermal Study}

Thermal decomposition of the samples was observed by using Hitachi STA7200 thermogravimetric analyzer. Thermograms of the films were observed from ambient to $600{ }^{\circ} \mathrm{C}$ at a heating rate of $10{ }^{\circ} \mathrm{C} \mathrm{min}^{-1}$ in a nitrogen atmosphere. To record thermograms of prepared samples, dried alumina powder $\left(\mathrm{Al}_{2} \mathrm{O}_{3}\right)$ was utilized as reference material and a sample holder made up of ceramic was used. To maintain the temperature uniformity of the sample, small amounts of samples $(4-7 \mathrm{mg})$ were taken. To prevent unwanted oxidation and to create an inert atmosphere, nitrogen was used to purge for 30 minutes before each run. The slope of Broido method gives the value of activation energy $\left(E_{a}\right)$, by substituting the value of R. In the same way, the activation energies were evaluated by Horowitz-Metzger and Coats-Redfern. Final equations were given in Table-1.

\section{FTIR Spectra}

Structural changes induced in PVA with the incorporation of different concentration of fiber was analyzed with the help of FTIR (ABB MB 3000 IR spectrophotometer) in the frequency range of 4000-600 $\mathrm{cm}^{-1}$. 
RASĀYAN J. Chem.

Vol. 14 | No. 4 |2224-2235| October- December | 2021

Table-1: Single Heating Rate Kinetic Methods for the Calculation of Activation Energy

\begin{tabular}{c|c|c}
\hline Methods & Final Expression & Plots \\
\hline Broido $^{17}$ & $\ln \ln \frac{1}{y}=\ln \left(\frac{R Z T_{m}^{2}}{E_{\alpha} \beta}\right)-\frac{E_{a}}{R T}$ & $\ln \ln \left(\frac{1}{y}\right)$ vs $\frac{1}{T}$ \\
\hline Horowitz- $_{\text {Metzger }}{ }^{19}$ & $\ln \left\{\ln \left(\frac{1}{1-\alpha}\right)\right\}=-\frac{E_{a} \theta}{R T_{S}^{2}}+$ constant & $\ln \ln \left(\frac{w_{0}}{w_{t}}\right)$ vs $\theta$ \\
\hline Coats-Redfern $^{18}$ & $\ln \frac{g(\alpha)}{T^{2}}=\ln \frac{A R\left(1-2 R T / E_{a}\right)}{\varphi E_{a}}-\frac{E_{a}}{R T}$ & $\ln \frac{g(\alpha)}{T^{2}}$ vs $\frac{1}{T}$ \\
\hline
\end{tabular}

\section{UV-Vis Spectra}

UV-Visible spectral analysis of the composite thin films was performed on UV-2550 UV-Visible Spectrophotometer Shimadzu. The comparison of the observed absorbance, \% transmittance and absorption edge were made and their optical properties have been visualized.

\section{Scanning Electron Microscopy (SEM)}

Surface morphology of PVA, PVA/CMC and PVA/CMC/CF-12.5\% were recorded using JEOL scanning electron microscope.

\section{Biodegradation Studies}

To study the degradation of carrot fiber-reinforced composites under natural conditions that may result in complete or partial eradication of materials from the ecosystem, the prepared thin films were subjected to both soil and compost environments separately. The bacterial flora responsible for the degradation study grew under natural conditions. Biodegradation progress of the composites was monitored in terms of $\%$ weight loss as well as chemical changes occurring therein. The results were interpreted with the help of UV and IR spectroscopy.

\section{Degradation by Compost}

Degradation of PVA/CMC/CF composite films was studied by measuring \% weight loss with time (in days) in a compost environment. The results were inferred for a total period of 28 days with an intermittent incubation period of 4 days. The samples having dimensions $(3.5 \mathrm{~cm} \times 1.5 \mathrm{~cm} \times 0.1 \mathrm{~cm})$ were kept in a degradation assembly at a depth of $5 \mathrm{~cm}, 25^{\circ} \mathrm{C}$ and relative humidity $50 \%$. Water was injected regularly after every two days. The samples were taken out after regular intervals of four days, deionized water was utilized to wash them properly and dried in a vacuum to get constant weight and finally submitted for spectral analysis. The results of IR and UV-spectra are provided in the supplementary file (I).

\section{Soil Burial Degradation}

Soil burial is also one of the natural degradation methods. The studies conducted in compost were repeated under similar conditions in the soil. The IR and UV-spectra of biodegradation studies have been attached in the supplementary file (II).

\section{Percentage Weight Loss of Samples after Degradation}

Weight loss \% of samples was calculated by using the equation:

$$
\% \text { Weight Loss }=\frac{W_{0}-W_{t}}{W_{0}} \times 100
$$

Where $w_{0}$ is the weight of the sample initially, $w_{t}$ is weight of the sample after time ' $t$ '. 
RASĀYAN J. Chem.

Vol. 14 | No. 4 |2224-2235| October- December | 2021

\section{Tensile Testing}

The tensile strength of the composite thin films was analyzed using Texture Profile Analyser (Stable microsystem). Samples were in the form of ASTM D882 standards. The separation distance of samples from grip position was $50 \mathrm{~mm}$ with $10 \mathrm{~mm} \mathrm{~min}^{-1}$ cross-head speed of the machine. Tensile strength and Young's Modulus of the samples were expressed in MPa concerning fiber loading.

\section{Thermal Analysis}

\section{RESULTS AND DISCUSSION}

Figure-1(a) and 1(b) represents the TG and DTG curve of biofilms. The data from TG and DTG curves are summarized in Table-2. A slight weight loss is observed at $60-170{ }^{\circ} \mathrm{C}$ due to the elimination of coordinated water molecules in TG curves of all samples.

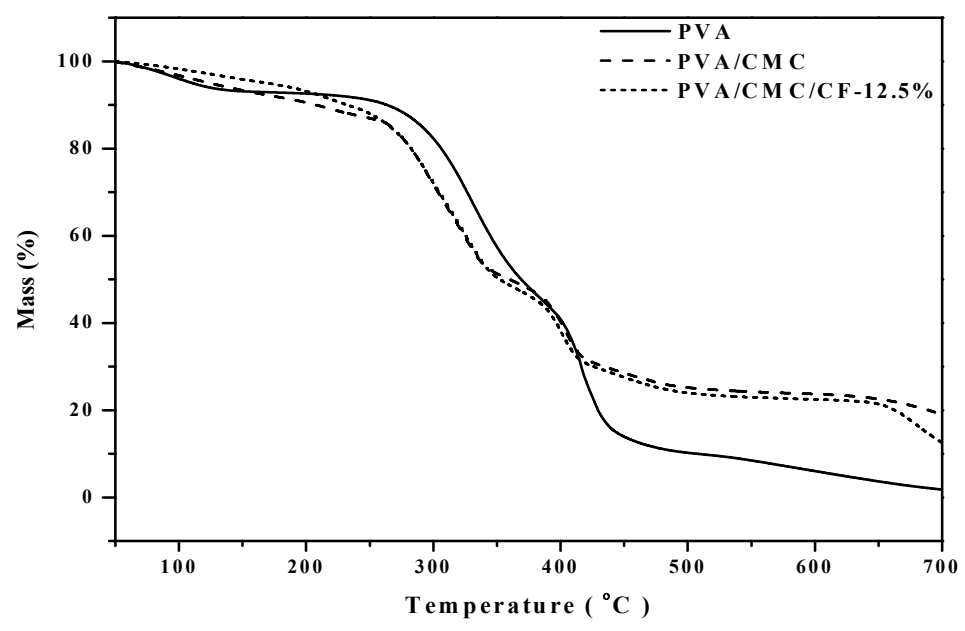

Fig.-1:(a) TG Curves of PVA-Carrot Fiber Composites at a Heating Rate of $10^{\circ} \mathrm{C} \mathrm{min}^{-1}$ in a Nitrogen Atmosphere

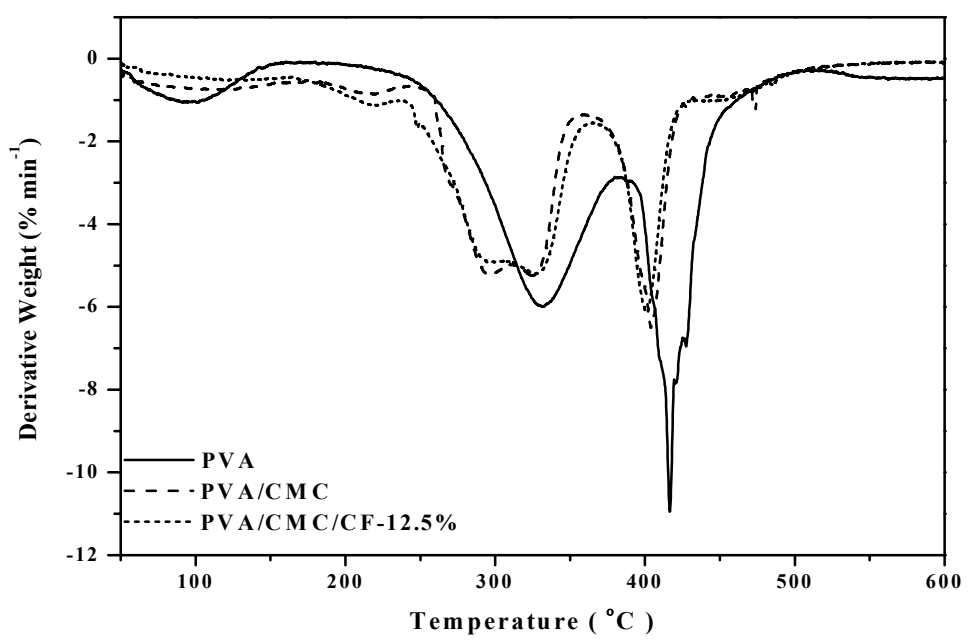

Fig.-1:(b) DTG Curves of PVA-Carrot Fiber Composites at a Heating Rate of $10^{\circ} \mathrm{C} \mathrm{min}^{-1}$ in a Nitrogen Atmosphere

As already reported [20] the degradation of PVA is a two step-mechanism and is also confirmed from the DTG curve. For neat PVA, onset degradation temperature $\left(\mathrm{T}_{\mathrm{o}}\right)$ be $236.3{ }^{\circ} \mathrm{C}$, offset degradation temperature $\left(\mathrm{T}_{\text {term }}\right)$ is $382.1{ }^{\circ} \mathrm{C}$ and temperature at which maximum weight loss occurred $\left(\mathrm{T}_{\mathrm{m} 1}\right)$ is 331.7 ${ }^{\circ} \mathrm{C}$. The presence of CMC-Na salt and carrot fiber changes the degradation behavior of PVA. For 
RASĀYAN J. Chem.

Vol. 14 | No. 4 |2224-2235| October- December | 2021

PVA/CMC, onset degradation temperature $\left(\mathrm{T}_{\mathrm{o}}\right)$ be $249.4{ }^{\circ} \mathrm{C}$, offset degradation temperature is $358.9^{\circ} \mathrm{C}$ and temperature at which maximum weight loss occurred $\left(\mathrm{T}_{\mathrm{m} 1}\right)$ is $325.3{ }^{\circ} \mathrm{C}$. On basis of onset degradation temperature $\left(\mathrm{T}_{\mathrm{o}}\right)$, it is observed PVA/CMC composites are thermally stable as compared to neat PVA, probably due to the introduction of $\mathrm{CMC}$ (in which $-\mathrm{CH}_{2} \mathrm{COOH}$ group is bound to some $-\mathrm{OH}$ group of natural cellulose) to PVA .By introducing carrot fiber (5-12.5 wt \%) to PVA/CMC, order of onset degradation temperature is $\mathrm{CF}-5 \%>\mathrm{CF}-7.5 \%>\mathrm{CF}-10 \%>\mathrm{CF}-12.5 \%$. Among all, $\mathrm{PVA} / \mathrm{CMC} / \mathrm{CF}-5 \%$ showed the highest thermal stability. The highest value of MWLR represents rapid and more thermal degradation for PVA/CMC/CF-10\%. Thermal profiles of CF-10\% and CF-12.5\% (Table-2), representing $12.5 \%$ are almost similar representing that $12.5 \%$ is the optimum level of carrot fiber.

Table-2: TG/DTG Data of PVA-Carrot Fiber Composites at a Heating Rate of $10^{\circ} \mathrm{C} \mathrm{min}^{-1}$

\begin{tabular}{c|c|c|c|c|c|c|c|c}
\hline \multirow{2}{*}{ Sample } & \multicolumn{4}{|c|}{ First Degradation Stage } & \multicolumn{4}{c}{ Second Degradation Stage } \\
\cline { 2 - 9 } & $\begin{array}{c}\mathrm{T}_{\mathrm{o}} \\
\left({ }^{\circ} \mathrm{C}\right)\end{array}$ & $\begin{array}{c}\mathrm{T}_{\mathrm{m} 1} \\
\left({ }^{\circ} \mathrm{C}\right)\end{array}$ & $\begin{array}{c}\mathrm{T}_{\text {term }} \\
\left({ }^{\circ} \mathrm{C}\right)\end{array}$ & $\begin{array}{c}\text { MWLR } \\
\left(\% \mathrm{~min}^{-1}\right)\end{array}$ & $\begin{array}{c}\mathrm{T}_{\mathrm{o}} \\
\left({ }^{\circ} \mathrm{C}\right)\end{array}$ & $\begin{array}{c}\mathrm{T}_{\mathrm{m} 2} \\
\left({ }^{\circ} \mathrm{C}\right)\end{array}$ & $\begin{array}{c}\mathrm{T}_{\text {term }} \\
\left({ }^{\circ} \mathrm{C}\right)\end{array}$ & $\begin{array}{c}\text { Char Yield at } \\
550{ }^{\circ} \mathrm{C}(\%)\end{array}$ \\
\hline PVA & 236.3 & 331.7 & 382.1 & 6.02 & 391.7 & 415.4 & 488.7 & 8.47 \\
\hline PVA/CMC & 249.4 & 325.3 & 358.9 & 5.28 & 362.7 & 403.2 & 428.2 & 24.2 \\
\hline PVA/CMC/CF-5\% & 242.9 & 319.2 & 361.4 & 5.24 & 363.7 & 403.1 & 431.2 & 23.6 \\
\hline PVA/CMC/CF-7.5\% & 239.2 & 320.2 & 356.8 & 5.70 & 365.3 & 400.2 & 433.3 & 23.1 \\
\hline PVA/CMC/CF-10\% & 236.8 & 321.0 & 355.2 & 6.29 & 366.9 & 399.9 & 435.4 & 22.6 \\
\hline $\begin{array}{c}\text { PVA/CMC/CF- } \\
12.5 \%\end{array}$ & 235.5 & 327.4 & 354.6 & 5.24 & 368.5 & 398.6 & 436.5 & 22.6 \\
\hline
\end{tabular}

On completion of degradation of the first stage, Weight (\%) remains almost same till the second degradation starts. Onset degradation temperature $\left(\mathrm{T}_{\mathrm{o}}\right)$ for the second stage is $391.7^{\circ} \mathrm{C}$ and $368.5^{\circ} \mathrm{C}$ for PVA and PVA/CMC/CF-12.5\%. In the second degradation stage, the parameters (maximum degradation temperature $\left(\mathrm{T}_{\mathrm{m} 2}\right)$ and termination temperature $\left.\left(\mathrm{T}_{\text {term }}\right)\right)$ represent only slight variation by the addition of carrot fiber. Char yield data is reported at $550{ }^{\circ} \mathrm{C}$ and the minimum value of char yield is observed for PVA/CMC/CF-12.5\%. It can be concluded that the introduction of carrot fiber to PVA causes early degradation of the biofilms.

\section{Degradation Activation Energy}

Kinetic parameters of the prepared biofilms have been calculated by the kinetic method. Kinetic parameters comprise temperature range for both degradation stages, activation energy $\left(E_{a}\right)$ and regression coefficient $\left(\mathrm{R}^{2}\right)$. The values calculated are summarized in Table- 3 .

Table-3: Activation Energies of PVA-Carrot Fiber Composites by Broido, Horowitz-Metzger and Coats-Redfern

\begin{tabular}{c|c|c|c|c}
\hline \multicolumn{5}{c}{ Methods } \\
\hline Biofilms & $\begin{array}{c}\text { Degradation } \\
\text { PVA }\end{array}$ & \multicolumn{3}{|c}{ Activation Energy $(\mathrm{kJ} / \mathrm{mol})$} \\
\cline { 3 - 5 } & $246-376$ & Broido & Horowitz-Metzger & Coats-Redfern \\
\hline PVA/CMC & $392-452$ & 50.30 & 50.59 & 43.14 \\
& $252-352$ & 66.28 & 52.64 & 59.50 \\
\hline PVA/CMC/CF-5\% & $364-424$ & 49.84 & 49.92 & 41.83 \\
& $244-354$ & 54.23 & 37.12 & 42.97 \\
\hline PVA/CMC/CF-7.5\% & $363-423$ & 47.99 & 46.76 & 38.91 \\
& $243-353$ & 40.77 & 29.16 & 41.08 \\
\hline PVA/CMC/CF-10\% & $365-425$ & 53.90 & 52.72 & 42.46 \\
\hline PVA/CMC/CF- & $242-352$ & 53.64 & 34.01 & 44.92 \\
$12.5 \%$ & $367-427$ & 54.35 & 53.57 & 38.75 \\
\hline
\end{tabular}


Activation energy calculated by using three approaches exposed several variations. The greater value of activation energy for PVA/CMC/CF composites in the first step indicates that the first degradation occurs slowly as compared to the second degradation stage.

The comparative activation energy values calculated by three methods are depicted in Figs.-2(a), 2(b) and 2(c).

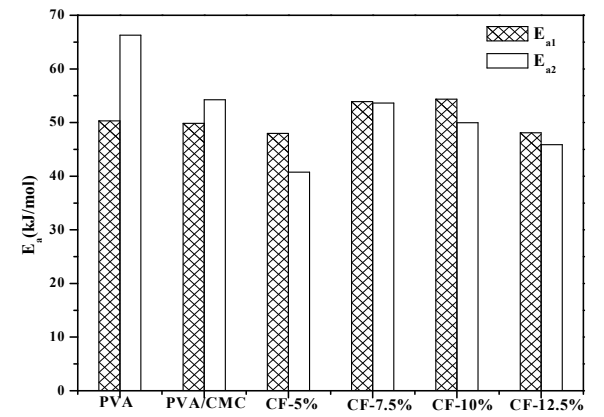

Fig.-2(a): Comparative Activation Energies of PVACarrot Fiber Composites by Broido Method

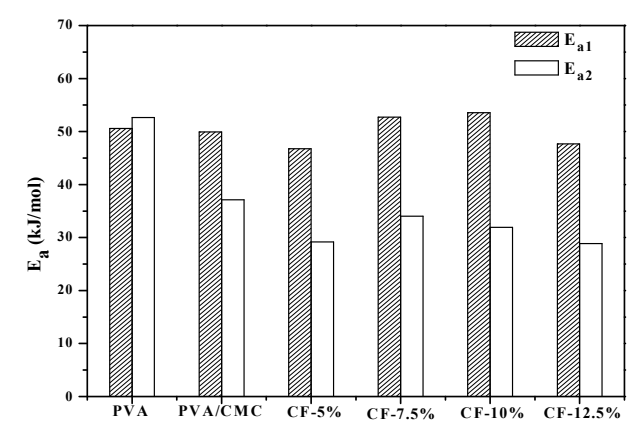

Fig.-2(b): Comparative Activation Energies of PVACarrot Fiber Composites by Horowitz-Metzger Method

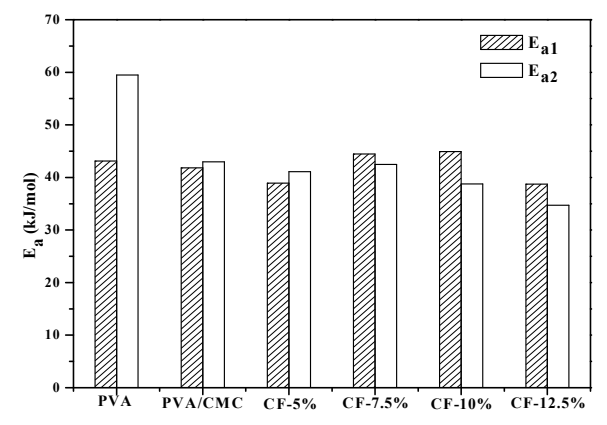

Fig.-2(c): Comparative Activation Energies of PVA-Carrot Fiber Composites by Coats-Redfern Method

\section{IR Spectra}

FTIR spectra of PVA/CMC/CF composites were recorded on ABB MB 3000 in the frequency range from $4000-600 \mathrm{~cm}^{-1}$ and represented in Fig.-3.

IR spectra of $\mathrm{PVA} / \mathrm{CMC} / \mathrm{CF}$ composites are important and used to study the compatibility of the composite films. All the observed spectra are almost similar but the peaks get intense as the carrot fiber \% increases. IR absorption bands at $3348 \mathrm{~cm}^{-1}$ and $3325 \mathrm{~cm}^{-1}$ are attributed to H-bonded -OH groups, additional bands at $2885 \mathrm{~cm}^{-1}$ are because of $-\mathrm{CH}_{2}$ stretching. The production of $\mathrm{CO}_{2}$ in the preparation of composite films is caused by the absorption band at $2361 \mathrm{~cm}^{-1}$. The absorption band at $1728 \mathrm{~cm}^{-1}$ shifts slightly to $1720 \mathrm{~cm}^{-1}$ and is a characteristic peak due to $-\mathrm{C}=\mathrm{O}$ stretching. Band values at 1589,1420 and $1342 \mathrm{~cm}^{-1}$ can be due to symmetrical and asymmetrical vibrations of $-\mathrm{COO}^{-}$group. In neat PVA, absorption band value at $1088 \mathrm{~cm}^{-1}$ is attributable to $\mathrm{C}-\mathrm{O}-\mathrm{H}$ stretching and these bands shift towards the higher value of $1103 \mathrm{~cm}^{-1}$ and $1111 \mathrm{~cm}^{-1}$ which can be because of strong intermolecular H-bonding between $-\mathrm{COO}^{-}$and $-\mathrm{OH}$ groups of PVA, CMC and $\mathrm{CF}$. A peak at $841 \mathrm{~cm}^{-1}$ is the characteristic peak of C-C stretching.

\section{UV-Vis Measurement}

The absorption spectra of PVA/CMC/CF composites are illustrated in Figure-4(a). It can be observed that composites have negligible absorbance in the region from 800 to $450 \mathrm{~nm}$. The characteristic absorption peak is observed in the wavelength region less than $450 \mathrm{~nm}^{21}$. An increase in the intensity of absorption 
RASĀYAN J. Chem.

Vol. 14 | No. 4 |2224-2235| October- December | 2021

is observed as the fiber concentration is increased. It means electronic interactions occur in prepared composite films. Figure-4(b) gives transmittance spectra of the prepared composites. From the figure it is clear as the fiber content is increased, \% transmittance decreases in the UV region from 200 to $300 \mathrm{~nm}$. Therefore PVA-Carrot fiber composites can block UV radiations and hence can be used in UV shield materials. $^{22}$

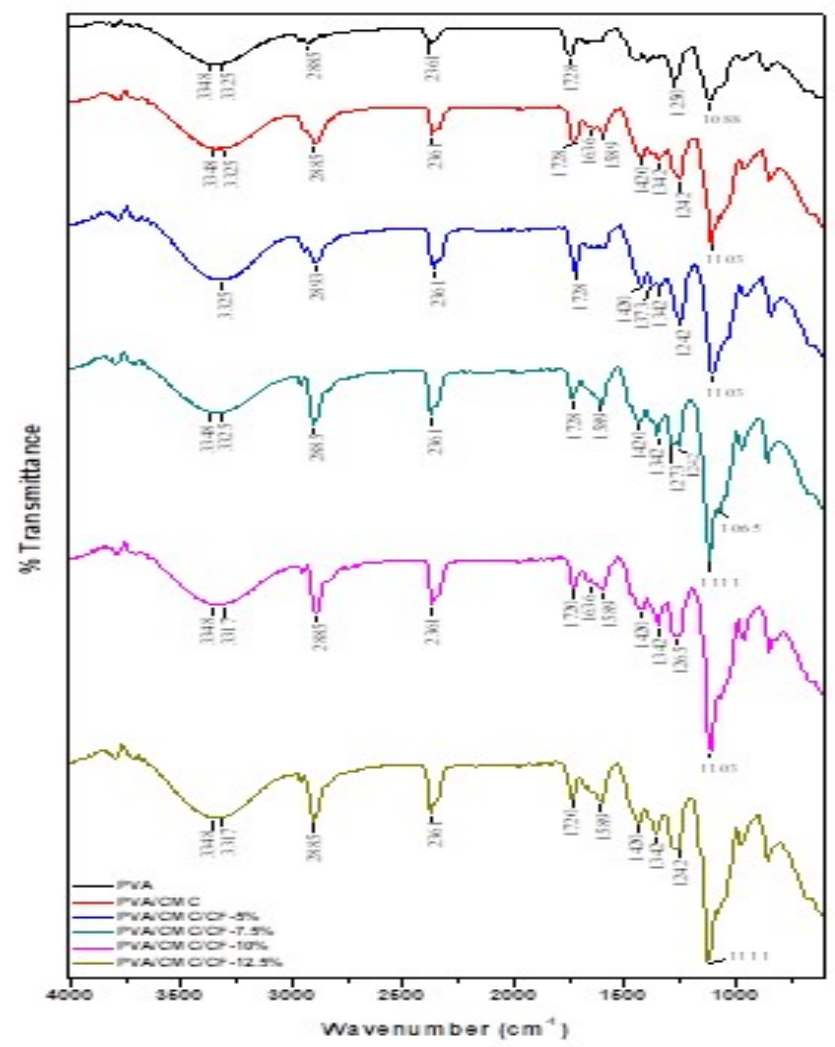

Fig.-3: FTIR Spectra of PVA-Carrot Fiber Composite Thin Films

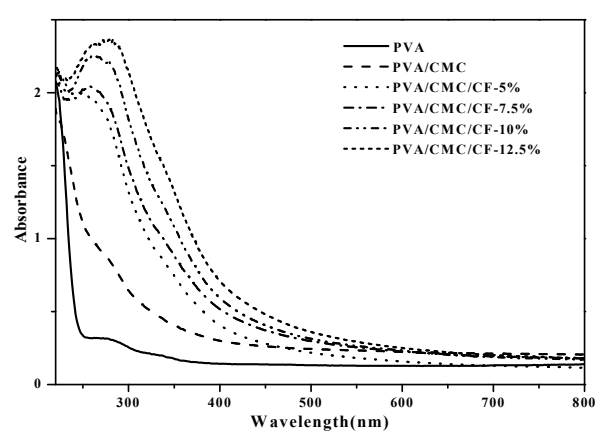

Fig.-4(a): Absorption Spectra of PVA-Carrot Fiber Composites

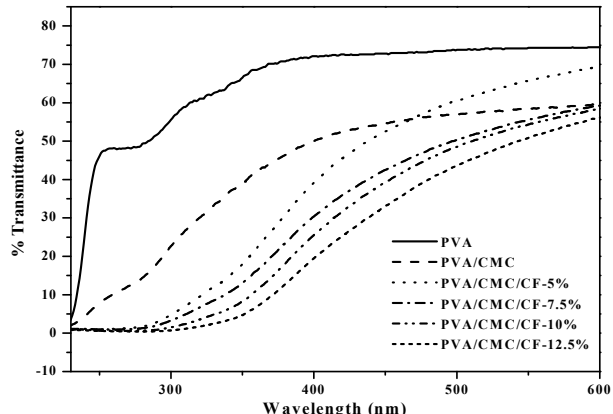

Fig.-4(b): Transmittance Spectra of PVA-Carrot Fiber Composites

The absorption coefficient $(\alpha)$ can be calculated using Beer Lambert's formula:

$$
\alpha=2.303(\mathrm{~A} / \mathrm{d})
$$

Where $\mathrm{A}$ is the absorbance of the composites and $\mathrm{d}$ is the sample thickness. Figure-4(c) represents the variation of absorption coefficient with energy for PVA-Carrot fiber composites. It is clear from the graph that the absorption edge for the prepared composite films shifts towards the lower value on the addition of carrot fiber. The shift in absorption edge indicating that the value of photon energy decreases which 
means the material is capable of absorbing UV radiations of lower energy along with higher energy and thus they provide better shielding against UV-radiations for all the prepared composites promoting their optical properties. ${ }^{21}$

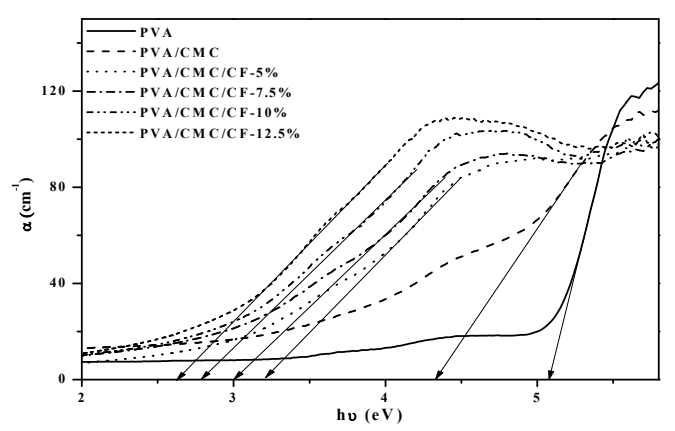

Fig.-4(c): Absorption Coefficients Versus Photon Energy for PVA-Carrot Fiber Composites

\section{Morphology Studies}

Morphologies of the processed composite thin films have been executed at 2500 magnification by SEM (Scanning electron microscopy). Micrographs of neat PVA, PVA/CMC and PVA/CMC/CF-12.5\% are given in Fig.-5. The micrograph of neat PVA (Fig.-5a) represents porous film structure. By introducing CMC to PVA, cross-linking occurs between PVA/CMC in Figure 5(b) and it is also clear from the tensile data in which tensile strength of PVA is increased from 9.85 $\mathrm{MPa}$ to $18.11 \mathrm{MPa}$ in PVA/CMC Contraction in porous structure to the produced films by the introduction of carrot fiber is observed in Fig.-5(c) and is also manifest from the tensile data. CMC and CF get entrapped in between the voids improving the adhesion between $\mathrm{CF}, \mathrm{CMC}$ and PVA.
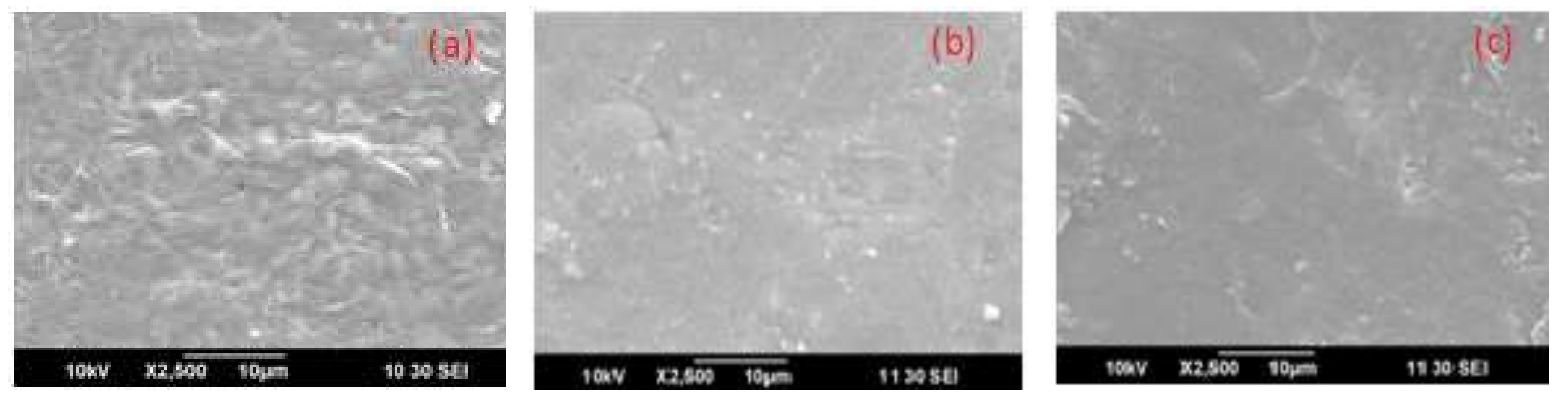

Fig.-5: SEM Micrographs of the Composite Thin Films (a) Neat PVA (b) PVA/CMC (c) PVA/CMC/CF-12.5\%

\section{Tensile Testing}

Tensile strength and Young's Modulus of the composite thin films were evaluated and expressed in Fig.6(a) and Fig.-6(b). The tensile strength of PVA is $9.85 \mathrm{MPa}$ as reported earlier by Tawab et al. ${ }^{23}$ and PVA/CMC is $18.11 \mathrm{MPa}$ which is much near to the value obtained by Buanz et al. ${ }^{24}$ and is higher than the expressed values by Tajeddin et al. ${ }^{25} \mathrm{By}$ incorporation of Carrot fiber to PVA/CMC, tensile strength decreases and is minimum for CF-5\% loading. As the loading of carrot fiber is increased, tensile strength increases and is maximum for fiber loading of $12.5 \%$. This represents that the hardness of films increases concerning fiber loading (Fig.-6a). Young's Modulus also increases from 1.65 MPa to 2.27 MPa with an increase in fiber concentration from $5 \%$ to $12.5 \%$ in PVA(Fig.-6b).

\section{Biodegradation in Soil and Compost}

Because of the chemically and thermal stability of PVA, it is resistant to degrade in most physiological environments and the introduction of $\mathrm{CMC}$ (in which $-\mathrm{CH}_{2} \mathrm{COOH}$ group is bound to some - $\mathrm{OH}$ group of natural cellulose) to PVA results in the improvement of its biodegradable properties ${ }^{29}$ [Fig.-7a and 7b]. 
RASĀYAN J. Chem.

Vol. 14 | No. 4 |2224-2235| October- December | 2021

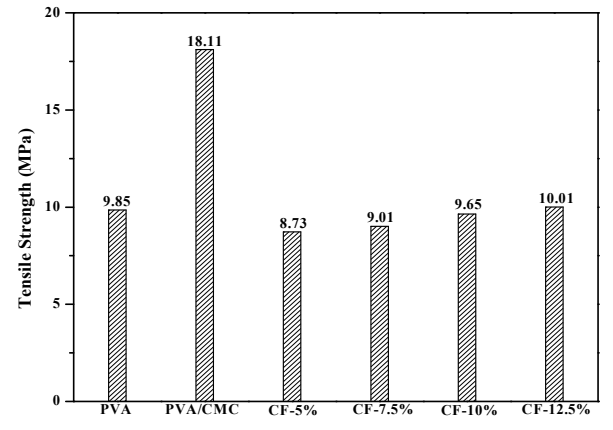

Fig.-6(a): Tensile Strength of Composite Thin Films

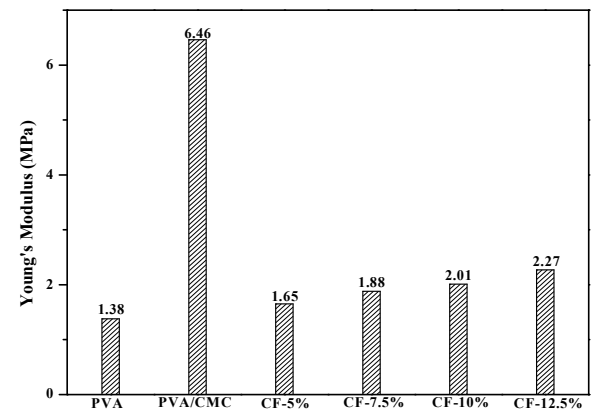

Fig.-6(b): Young's Modulus of Composite Thin Films

Degradation of PVA, PVA/CMC and PVA/CMC/CF composites was carried out by placing the samples in soil and compost for 28 days (Fig.-7a and 7b). The samples were removed after every 4 days, washed carefully, dried and finally weighted. However, weight loss percentage is not the best approach for evaluating the degradation of the samples but can be implemented for preliminary studies. In the last days of degradation, soil and compost may get impeded in the samples and it is not easy to expel them without damaging the samples. ${ }^{26}$ It was further observed that biodegradability in carrot fiber incorporated films was more than PVA but was comparable to PVA/CMC films suggesting that the prepared composite films retained the biodegradable quality. The experimental films have an added advantage with greater UV protection as the \% transmittance decreased with increment in fiber content.

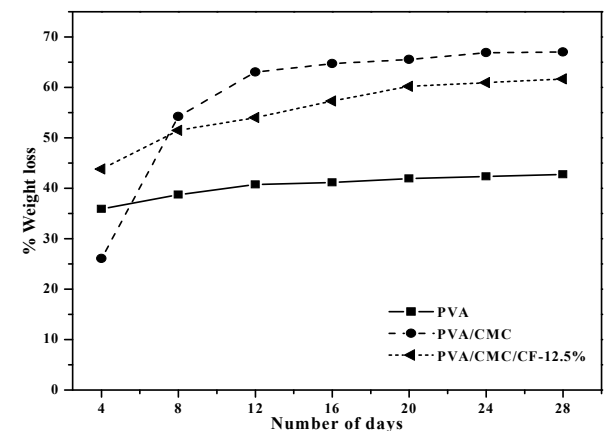

Fig.-7(a): \% Weight loss of (a) neat PVA (b) $\mathrm{PVA} / \mathrm{CMC}$ (c) PVA/CMC/CF-12.5\% in Compost

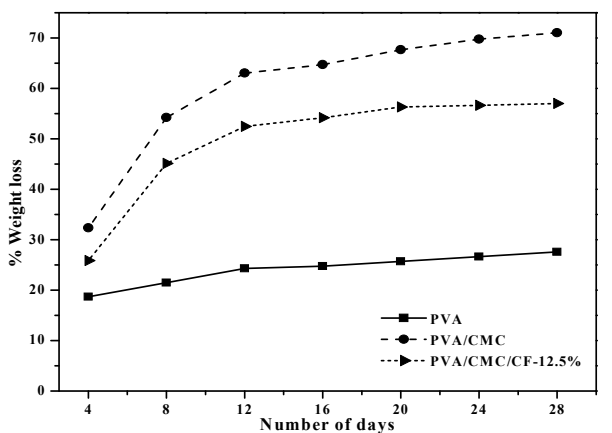

Fig.-7(b): \% Weight loss of (a) neat PVA (b) $\mathrm{PVA} / \mathrm{CMC}$ (c) PVA/CMC/CF-12.5\% in Soil

In the present study, we have also introduced FTIR and UV spectral data of the composites and some interesting results were obtained at our hands. Figures are given in supplementary data (I) present the UV spectrum of different composites prepared. It can be observed that in PVA, the pattern of absorbance in different wavelengths is almost similar except that after 8 days of inhibition where the chromophoric/auxochromic groups disappear in the experimental wavelength. The spectral results of PVA/CMC suggest that the degradation cycle is either repeated or enters a subsequent degradation cycle after 8 days of incubation in compost. We found that peculiar peaks diminished first after 8 days of exposure, appeared again after 12 days and tend to disappear again after 16 days. The results for the third cycle i.e. after 24 days of exposure to micro-organisms could not be recorded as the composites became too fragile to handle and more than $50 \%$ of the weight was lost. The UV spectra of carrot fiber-reinforced composites also suggested that structural changes occurred with incubation time. As the composites are formed of different constituents such as PVA, PEG, CMC, cellulose, hemicelluloses, lignin etc. so, it was not practicable to determine the exact structural changes. However, structural variations of different composites with time are clear from these results. 
RASĀYAN J. Chem.

Vol. 14 | No. 4 |2224-2235| October- December | 2021

Structural variations have also been indicated in FTIR spectral studies of different films [Figures provided in supplementary data (I)]. In the degradation studies of neat PVA, we observed that stretching frequencies due to bound $\mathrm{OH}$ group (3240-3441 $\mathrm{cm}^{-1}$ ) diminished after 8 days of degradation and this region becomes clear. A similar change was observed in the case of PVA/CMC films, where the peaks due to free $\mathrm{OH}$ stretching frequency $\left(3618-3749 \mathrm{~cm}^{-1}\right)$ appeared and variation in the region of $\mathrm{C}=\mathrm{O}(1682-$ $1744 \mathrm{~cm}^{-1}$ ) can be attributed to aldehydic, ketonic or carboxyl group. The stretching frequencies in the region (2854-2924 $\mathrm{cm}^{-1}$ ) can be assigned either to $-\mathrm{OH}$ of carboxyl group or aldehydic $-\mathrm{CHO}$. Similar results have been observed in all the composite films, where $\mathrm{OH}$ stretching frequencies $\left(3618-3749 \mathrm{~cm}^{-1}\right)$ and peaks related to the aldehyde group or carboxyl group appeared. Based upon these observations we here proposed that initially the $\mathrm{OH}$ group of either PVA, vicinal diol functionalities of cellulose reinforced with carrot fiber, or plasticizer used (PEG) get oxidized by micro-organisms into aldehydic/ketonic moieties resulting in decreased intensities in $\mathrm{OH}$ stretching frequency region and appearance of observed peaks in the $\mathrm{C}=\mathrm{O}$ region at their respective position. Further oxidation to carboxyl moiety cannot be ignored. It becomes impossible to interpret the conversion of $\mathrm{CHO}$ to $\mathrm{COOH}$ in a polymer as at any time both the functionalities will be present but the loss of weight with time suggests this hypothesis that the $\mathrm{COOH}$ is further decarboxylated leading to the unsaturated group in the polymer composites. The $\mathrm{C}=\mathrm{C}$ bond stretch is also quite visible in the prescribed range $\left(1651 \mathrm{~cm}^{-1}\right)$, which in the starting material is to a lesser extent. Unsaturation created the sites for oxidation followed by fragmentation, re-oxidation and decarboxylation leading to loss of weight and is the loss of carbon content. Similar structural variations were observed for degradation studies in soil [Figures in the supplementary file (II)] with the difference that degradation is more in compost than in soil (as discussed earlier).

Similar results of PVA degradation have been previously reviewed by Leja et al. ${ }^{27}$ and Gulati et al. ${ }^{28}$. Based on the degradation mechanism proposed by Leja et al. ${ }^{27}$ we here illustrate the degradation mechanism of the composites prepared [Fig.-8a] and [Fig.-8b]. Different enzymes present in soil and compost bacteria are responsible for this degradation. It is evident from IR spectral data obtained after different incubation interval that at first oxidation of cellulosic material present in the carrot fiber take place followed by decarboxylation.

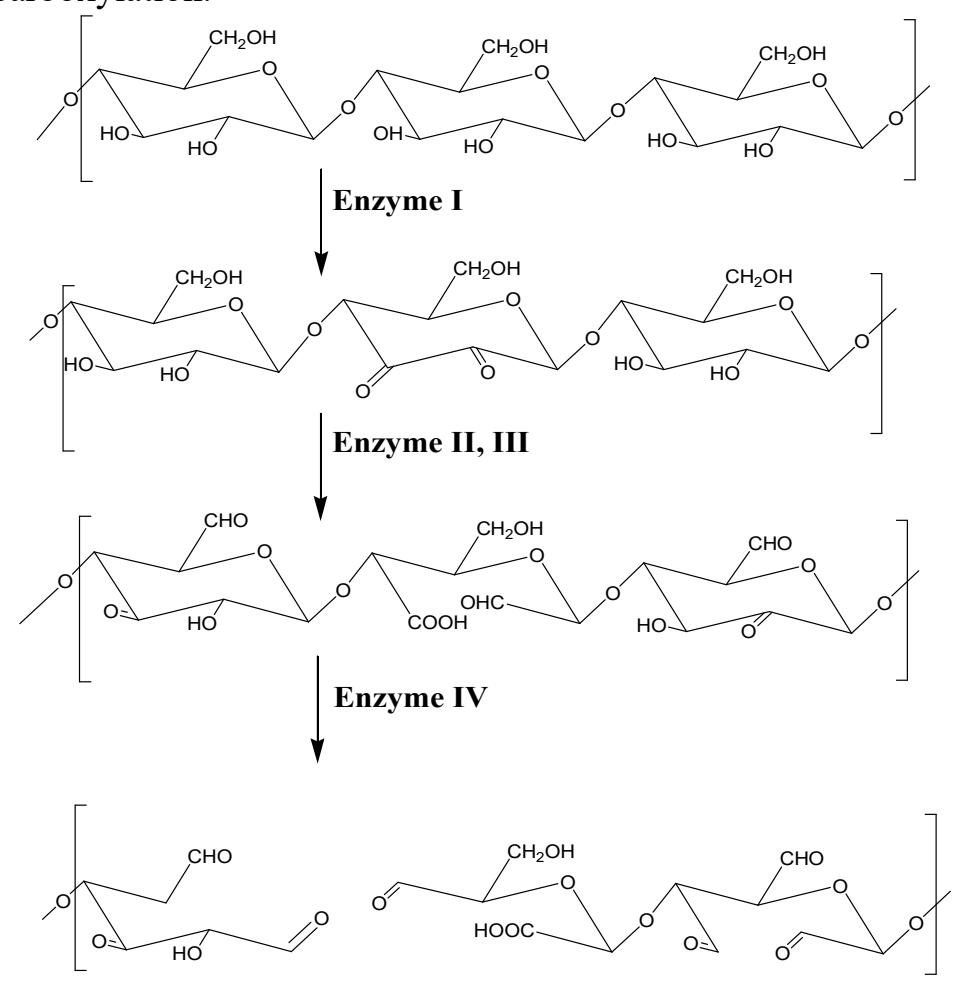

Fig.-8(a): Enzyme I and II are oxidases, Enzyme III and Enzyme IV belong to classes lyases and decarboxylases, respectively 


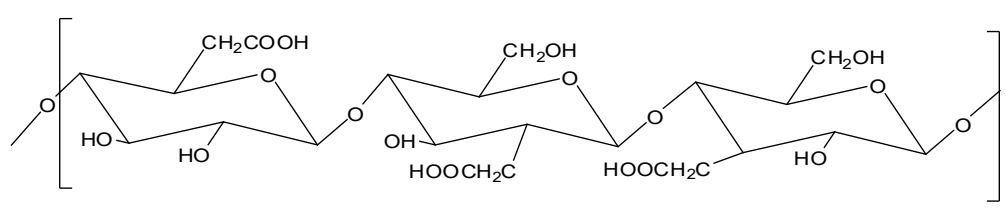

Enzyme III
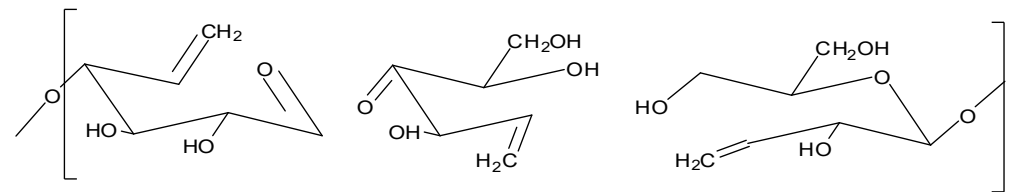

Fig.-8(b) Enzyme III belong to class decarboxylases

During decarboxylation carbon content is lost along with the fragmentation of the polymer composite. Any of the -OH group positioned at 2, 3, or 6 of the cellulosic component of the carrot fiber can undergo oxidation but $-\mathrm{OH}$ at position 6 is more vulnerable. The proposed mechanism is further strengthened when we observed the degradation pattern of PVA-CMC. Here the support initially contains carboxyl groups therefore the site for decarboxylases is already available. Therefore, these composite films results in the improvement of its applications in the field of agriculture, food packaging as well as in drug delivery. ${ }^{29}$

\section{CONCLUSION}

Carrot fiber was obtained from the residue left after juicing and the effect of carrot fiber reinforcement on PVA and PVA/CMC have been studied. Significant changes were observed and interpreted using FTIR, thermogravimetric analysis, UV-visible, biodegradation, SEM and tensile testing. CF introduction to PVA causes the early degradation of the composites as determined using TG/DTG curves and is also clearly observed from the degradation studies in the soil as well in compost. PVA/CMC/CF composites showed the enhanced values of absorbance, thus promoting the applications of composites in UV shield materials. Change in structure from macroporous to microporous is observed from the SEM micrographs. Tensile strength results revealed the optimum value of fiber loading i.e. $12.5 \mathrm{wt} \%$ which is also observed from thermal data. Thus, carrot fiber introduction to PVA/CMC can be helpful to prepare eco-friendly and lowcost composites, promoting their applications in the packaging materials.

\section{ACKNOWLEDGEMENT}

Financial support from the CSIR, New Delhi as Senior Research Fellowship, award letter no. 21/06/2015 (i) EU-V to Seema Rani is gratefully acknowledged. Acknowledgment is also due to Chairman, Chemistry department, Kurukshetra University, Kurukshetra for providing required laboratory facilities. Thanks are also due to Principal and Staff of Dr. B.R.A. Govt. College, Kaithal for their moral support.

\section{REFERENCES}

1. L. Averous and N. Boquillon, Carbohydrate Polymers, 56, 111(2004), https://doi.org/10.1016/j.carbpol.2003.11.015

2. A.K. Mohanty,M. Misra and G. Hinrichsen, Macro-Molecular Materials and Engineering, 276-277, 1(2000), https://doi.org/10.1002/(SICI)1439-2054(20000301)276:1<1::AID-MAME1>3.0.CO;2-W

3. Z.N. Azwa, B.F. Yousif, A.C. Manalo and W. Karunasena, Materials \& Design, 47, 424(2013), https://doi.org/10.1016/j.matdes.2012.11.025

4. M. Jawaid and H.P.S. Abdul Khalil, Carbohydrate Polymers, 86, 1(2011), https://doi.org/10.1016/j.carbpol.2011.04.043

5. D. Puglia, J. Biagiotti and J.M. Kenny, Journal of Natural Fibers, 1(3), 23(2005). https://doi.org/10.1300/J395v01n03 03

6. Sharma, S. Karki, N.S. Thakur and S. Attri, Journal of Food Science and Technology, 49, 22(2012), https://doi.org/10.1007/s13197-011-0310-7 
RASĀYAN J. Chem.

Vol. 14 | No. 4 |2224-2235| October- December | 2021

7. P. Asokan, M. Firdoous and W. Sonal, Reviews on Advanced Materials Science, 30, 254(2012).

8. G. Siqueira, K. Oksman, S.K. Tadokoro and A.P. Mathew, Composites Science and Technology, 123, 49(2016), https://doi.org/10.1016/j.compscitech.2015.12.001

9. I.G. Guimarães, E.G.T. Menezes, A.C. Rodrigues, T.F. da Silva, E.V. de B. Vilas Boas, K. C. dos Reis and I.R.N. de Oliveira, Industrial Crops and Products, 89, 285(2016), https://doi.org/10.1016/j.indcrop.2016.05.024

10. M.M. Ibrahim,W.K. El-Zawawy and M.A. Nassar, Carbohydrate Polymers, 79, 694(2010), https://doi.org/10.1016/j.carbpol.2009.09.030

11. K. Gulati, S. Lal, P.K. Diwan and S. Arora, International Journal of Applied Engineering Research, 14, 170(2019).

12. S. Arora, M. Kumar and M. Kumar, Journal of Applied Polymer Science, 127, 3877(2013), https://doi.org/10.1002/app.37705

13. S. El-Sayed, K.H. Mahmoud, A.A. Fatah and A.Hassen, Physica B: Condensed Matter, 406, 4068(2011), https://doi.org/10.1016/j.physb.2011.07.050

14. P. Rachtanapun, W. Tongdeesoontorn, P. Sriburi, L.J. Mauer and S. Wongruong, Chemistry Central Journal, 5, 6(2011), https://doi.org/10.1186/1752-153X-5-6

15. C. Díaz-Cruz, G. Alonso Nuñez, H. Espinoza-Gómez and L.Z. Flores-López, European Polymer Journal, 83, 265(2016), https://doi.org/10.1016/j.eurpolymj.2016.08.025

16. M.K. Yalinkilic, E.D. Gezer, M. Takahashi, Z. Demirci, R. Ilhan and Y. Imamura, European Journal of Wood and Wood Products, 57, 351(1999).

17. A. Broido, Journal of Polymer Science Part A-2: Polymer Physics, 7, 1761(1969), https://doi.org/10.1002/pol.1969.160071012

18. A.W. Coats and J.P. Redfern, Nature, 201, 68(1964), https://doi.org/10.1038/201068a0

19. H.H. Horowitz and G. Metzger, Analytical Chemistry, 35, 1464(1963), https://doi.org/10.1021/ac60203a013

20. S. Arora, M. Kumar and M. Kumar, Journal of Reinforced Plastics and Composites, 31, 85(2012), https://doi.org/10.1177/0731684411431765

21. S.B. Aziz, H.M. Ahmed, A.M. Hussein, A.B. Fathulla, R.M. Wsw and R.T. Hussein, Journal of Materials Science: Materials in Electronics, 26, 8022(2015), https://doi.org/10.1007/s10854-0153457-6

22. M. Zhu, D. Li, P. Shi, F. Hong and R. Su, Bioresource Technology, 115, 136(2011), https://doi.org/10.1016/j.biortech.2011.12.085

23. K.A. Tawab, M.M. Magida and S.M. Ibrahim, Journal of Polymers and the Environment, 19, 440(2011), https://doi.org/10.1007/s10924-011-0294-4

24. A.B.M. Buanz, C.C. Belaunde, N. Soutari, C. Tuleu, M.O. Gul and S. Gaisford, International Journal of Pharmaceutics, 494, 611(2015), https://doi.org/10.1016/j.ijpharm.2014.12.032

25. B. Tajeddin and N. Ramedani, Iranian Journal of Chemistry and Chemical Engineering, 35, 9(2016), https://doi.org/10.30492/ijcce.2016.22053

26. C.R. Di Franco, V.P. Cyras, J.P. Busalmen, R.A. Ruseckaite and A.Vázquez, Polymer Degradation and Stability, 86, 95(2004), https://doi.org/10.1016/j.polymdegradstab.2004.02.009

27. K. Leja and G. Lewandowicz, Polish Journal of Environmental Studies, 2, 255(2010).

28. K. Gulati, S. Lal and S. Arora, SN Applied Sciences, 1, 1416(2019), https://doi.org/10.1007/s42452$\underline{019-1462-8}$

29. H.V. Khoramabadi, M. Arefian, M.Hojjati, I. Tajzad, A. Mokhtarzade, M. Mazhar and A. Jamavari, Journal of Composites and Compounds, 2, 69(2020), https://doi.org/10.29252/jcc.2.2.2

[RJC-6445/2021] 